\title{
POPULATION GROWTH AND PREFERENCE CHANGE IN A GENERALIZED SOLOW GROWTH MODEL WITH GENDER TIME DISTRIBUTIONS
}

\author{
Wei-Bin Zhang \\ Ritsumeikan Asia Pacific University, Japan \\ wbzl@apu.ac.jp
}

\begin{abstract}
The study builds a model of dynamic interactions between the birth rate, the mortality rate, the population, wealth accumulation, time distribution between work, leisure and children caring, habit formation and preference change. The production technology and markets are built on the Solow growth model. We base our modeling the population dynamics on the Haavelmo population model and the Barro-Becker fertility choice model. This study takes account of habit formation and preference change. Although it is influenced by the Ramsey growth theory with time preference and habit formation, it uses Zhang's approach to the household with habit formation and preference change. We synthesize different dynamic forces in a compact framework, using the utility function proposed by Zhang. Analytically, we focus on transitional processes as well as economic equilibrium. As the economic system is given by autonomous nonlinear differential equations, it is not easy to analyze its behavior. We simulate the model to demonstrate the existence of an equilibrium point and plot the motion of the dynamic system. We examine the effects of changes in weights given to the habit stock of children, the wife's wage rate having negative impact on the propensity to have children, the wife weighing less the habit stock of leisure time, the wife's habit stock of leisure time having negative impact on the husband's propensity to use leisure time, the wife's wage rate having negative impact on the husband's propensity to use leisure time, woman's human capital being improved, a rise in the total factor productivity, and the mother spending more time on each child fostering.
\end{abstract}

Keywords: habit stock; preference change; gender discrimination; propensity to have children; birth and mortality rate; population growth; gender difference in time distribution; wealth accumulation.

JEL classification: J11; J12; J13; N3.

\section{Introduction}

The main purpose of this study is to examine dynamic relations between economic growth, population growth, and preference change. Preference change has been recognized by economists even since Adam Smith, it may be claimed that economics still lacks proper analytical frameworks for analyzing interactions between preference change, population change, and economic growth. In The Theory of Moral Sentiments, Adam Smith observes: "The man who lives within his income is naturally contented with his situation, which, by continual, though small accumulations, is growing better and better every day. He is enabled gradually to relax, both in the rigour of his parsimony and in the severity of his application; and he feels with double satisfaction this gradual increase of ease and enjoyment, from having felt before the hardship which attended the want of them." Fisher (1930: 72) observes the influence of wealth and income on preference difference: "Poverty bears down heavily on all portions of a man's expected life. But it increases the want for immediate income even more than it increases the want for future income." According to Fisher (1930: 81): "In the case of primitive races, children, and other uninstructed groups in society, the future is seldom considered in its true proportions." Fisher also discusses interactions between cultures and other factors such 
as self-control, habit, concerns for the lives of other people, and fashion. There are empirical studies which confirm existence of interdependent relations between preference changes and other changes in social and economic conditions (Fuchs, 1982; Horioka; 1990; Olsen, 1993; Sheldon, 1997, 1998; Becker and Mulligan, 1997; Kirby et al. 2002; and Chao et al., 2009). The modeling of preference change in this study is influenced by the ideas about the time preference change and habit formation in the Ramsey-type neoclassical growth theory. Becker and Mulligan (1997: 729) observe: "Time preference plays a fundamental role in theories of saving and investment, economic growth, interest rate determination and asset pricing, addiction, and many other issues that are getting increasing attention from economists. Yet, since Samuelson's (1937) discounted utility model, rates of time preference are almost invariably taken as "given" or exogenous, with little discussion of what determines their level." An early formal modeling of endogenous time preference was proposed by Uzawa (1968). There are other studies on the implications of endogenous time preference for the macroeconomy (Epstein and Hynes, 1983; Obstfeld, 1990; Shin and Epstein, 1993; Palivos et al. 1997; Drugeon, 1996, 2000; Stern, 2006; Meng, 2006; Dioikitopoulos and Kalyvitis, 2010). The studies show that endogeneity of time preference is necessary to properly deal with economic growth and development. This study applies the basic ideas in the literature of habit formation and preference change. The idea of habit formation or habit persistence was introduced to formal economic analysis by Duesenberry (1949). Becker (1992) explains: "the habit acquired as a child or young adult generally continue to influence behavior even when the environment changes radically. For instance, Indian adults who migrate to the United States often eat the same type of cuisine they had in India, and continue to wear the same type clothing." The idea of habit formation is applied to different economic issues (e.g., Pollak, 1970; Mehra and Prescott, 1985; Sundaresan, 1989; Abel, 1990; Constantinides, 1990; de la Croix, 1996; Ravn et al. 2006; and Campbell and Cochrane, 1999; Boldrin et al. 2001; Huang, 2012). This study applies these ideas to explain habit formation and preference change in a neoclassical growth model.

The economic production and markets are based on the neoclassical growth theory. The seminal paper in the field is the Solow model. The neoclassical growth theory is mainly concerned with endogenous physical capital or wealth accumulation in freely competitive markets (Solow, 1956; Burmeister and Dobell, 1970; Azariadis, 1993; Barro and Sala-i-Martin, 1995). The model of this study is built within the framework of neoclassical growth theory. We follow the Solow model in modeling economic production and wealth accumulation. This study introduces habit formation of children and endogenous preference change in having children to neoclassical growth theory. Since Malthus published his An Essay on the Principle of Population in 1798, different economists proposed different ideas about interdependence between population change and economic growth. In the last two hundred years countries have experienced different patterns of population changes. This study deals with dynamic interactions between wealth accumulation and population dynamics with endogenous birth rate, mortality rate and gender time distribution. Population change is the net result of birth rate and mortality rate. In the literature of population dynamics many factors are supposed to be related to birth rates (Barro and Becker, 1989; Becker et al., 1990; Kirk, 1996; Galor and Weil, 1996; Galor and Weil, 1999; Doepke, 2004; Adsera, 2005; Bhattacharya and Qiao, 2007; Manuelli and Seshadri, 2009; Chu et al., 2012; Bosi and Seegmuller, 2012; Hock and Weil, 2012; Varvarigos and Zakaria, 2013). Aging become a great concern in many modern economies. Given the population structure, aging is closely related to mortality rate (Cigno and Rosati, 1996; Robinson and Srinivasan, 1997; Schultz, 1993, 1998; Blackburn and Cipriani, 2002; Chakraborty, 2004; Hazan and Zoabi, 2006; Heijdra and Romp, 2008; Ludwig and Vogel, 2009; Lee and Mason, 2010; Balestra and Dottori, 2012; Lancia and Prarolo, 2012; and Ludwig et al., 2012). 
To explain birth and mortality rates we need to take account of gender differences in behaviour. As Flabbi (2010: 745) observes: "Even if wages and earnings for women and men in the United States have experienced a significant convergence in the 1970s and 1980s, their ratio has remained roughly constant at $75 \%$ since the mid-1990s... The United States is not an exception among OECD countries: they rank more or less average, with Northern European countries traditionally showing the lowest differentials and Japan the highest. These differentials persist after conditioning on observable productivity characteristics...." Endogenous preferences should help to explain complicated patterns of gender division of time (e.g., Goodfriend and McDermott, 1995; Kelly, 1997; Edmonds and Pavcnik, 2006). It should be noted that this study is to integrate three models by Zhang $(2012,2013,2015)$. Zhang (2015) develops a growth model with endogenous birth and mortality rates. Zhang (2012, 2013) builds the Solow-type models on the basis of the habit formation and time preference in the Ramsey-type growth theory. The rest of the paper is organized as follows. Section 2 defines the growth model with habit and preference dynamics. Section 3 deals with dynamic properties of the model and simulates the motion of the economy. Section 4 carries out comparative dynamic analysis studies effects of changes in some parameters on the system. Section 5 makes concluding remarks.

\section{The basic model}

The model is a synthesis of the three models by Zhang $(2012,2013,2015)$. The model is built on the Solow growth model in describing the production sector (Solow, 1956). The economy has a single production sector, producing a single commodity for consumption and investment. Capital depreciates at a constant exponential rate, $\delta_{k}$, which is independent of the manner of use. Technology of the production sector is characterized of constant returns to scale. All markets are perfectly competitive. Factors are inelastically supplied and the available factors are fully utilized at every moment. Saving is undertaken only by households. All earnings of firms are distributed in the form of payments to factors of production. Households own assets of the economy and distribute their incomes to consumption, child bearing, and wealth accumulation. The population of each gender is homogeneous. We assume that each family consists of husband, wife and children. All the families are identical. We use subscripts $q=1$ and $q=2$ to stand for man and woman respectively. We follow the same spirit as described by Albanesi and Olivetti (2009: 82): "Since the purpose of this paper is to study the joint determination of gender differentials in labor market outcomes and in the household division of labor, we abstract from modelling marriage decisions ...". We use $N(t)$ to stand for the population of each gender. Let $T_{q}(t)$ and $\bar{T}_{q}(t)$ stand for work time and time spent on taking care of children of gender $q$ and $\bar{N}(t)$ for the flow of labor services used in time $t$ for production. Let $N_{q}(t)$ stand for the qualified labor force of gender $q$. We have

$$
N_{q}(t)=h_{q} T_{q}(t) N(t), \quad \bar{N}(t)=N_{1}(t)+N_{1}(t),
$$

where $h_{q}$ is the level of human capital of gender $q$. 


\subsection{The production sector}

The production sector uses capital and labor as inputs. Let $K(t)$ stand for the capital stock at time $t$. We use $F(t)$ to represent the output level. The production function is

$$
F(t)=A K^{\alpha}(t) \bar{N}^{\beta}(t), \quad \alpha, \beta>0, \alpha+\beta=1,
$$

where $A$ is the total productivity of the production sector, and $\alpha$ and $\beta$ are respectively the constant output elasticities of capital and qualified labor input. Markets are competitive; thus labor and capital earn their marginal products, and firms earn zero profits. We denote $w(t)$ the wage rate of per unit of qualified work time in the labor market. The marginal conditions are

$$
r(t)+\delta_{k}=\frac{\alpha F(t)}{K(t)}, w(t)=\frac{\beta F(t)}{\bar{N}(t)},
$$

where $w_{q}(t)$ are the wage rates of per unit of work time by gender $q$

$$
w_{1}(t)=h_{1} w(t), \quad w_{2}(t)=h_{2} w(t) .
$$

\subsection{The current and disposable incomes}

We use an alternative approach to modelling consumer behaviour proposed by Zhang (1993). The representative household chooses the consumption level of commodity, leisure time, work time, number of children, as well as on amount of saving. We use $\bar{k}(t)$ to stand for wealth per household, i.e., $\bar{k}(t)=K(t) / N(t)$. The per household current income $y(t)$ from the interest and wage payments as follows

$$
y(t)=r(t) \bar{k}(t)+w_{1}(t) T_{1}(t)+w_{2}(t) T_{2}(t) .
$$

The total value of wealth that a representative household can sell to purchase goods and to save is equal to $\vec{k}(t)$. We assume that selling and buying wealth can be conducted instantaneously without any transaction cost. The per capita disposable income of the household is defined as the sum of the current income and the wealth available for purchasing consumption goods and saving

$$
\hat{y}(t)=y(t)+\bar{k}(t)
$$

\subsection{The cost of children caring}

Let $n(t)$ and $p_{b}(t)$ stand for the birth rate and the cost of birth at time. Following Zhang (2012, 2013), we assume that children will have the same level of wealth as that of the parent (see also Barro and Becker, 1989; Becker, 1981). In addition to the time spent on children, the cost of the parent is given by

$$
p_{b}(t)=n(t) \bar{k}(t)
$$


In some societies, women are the primary providers of child care. We consider the following relation between fertility rate and the parent's time on raising children

$$
\bar{T}_{q}(t)=\theta_{q} n(t), \theta_{q} \geq 0
$$

The specified function form implies that if the parents want more children, they spend more time on child caring. This requirement is strict as child caring tends to exhibit increasing return to scale.

\subsection{The budget and time constraint}

The household distributes the total available budget between saving, $s(t)$, consumption of goods, $c(t)$, and bearing children, $p_{b}(t)$. The budget constraint is

$$
p(t) c(t)+s(t)+\bar{k}(t) n(t)=\hat{y}(t)
$$

We consider that except work and child caring, parents also have their leisure. We denote the leisure time of gender $q$ by $\tilde{T}_{q}(t)$. An adult is faced with the following time constraint

$$
T_{q}(t)+\bar{T}_{q}(t)+\tilde{T}_{q}(t)=T_{0}
$$

where $T_{0}$ is the total available time for leisure, work and children caring. Insert (8) in (7)

$$
p(t) c(t)+s(t)+\bar{k}(t) n(t)+\bar{T}_{1}(t) w_{1}(t)+\bar{T}_{2}(t) w_{2}(t)+\tilde{T}_{1}(t) w_{1}(t)+\tilde{T}_{2}(t) w_{2}(t)=\bar{y}(t)
$$

where

$$
\bar{y}(t) \equiv(1+r(t)) \bar{k}(t)+\left(w_{1}(t)+w_{2}(t)\right) T_{0} .
$$

The right-hand side is the "potential" income that the family can obtain by spending all the available time on work. The left-hand side is the sum of the consumption cost, the saving, the opportunity cost of bearing children, and opportunity cost of leisure. Insert (6) in (9)

$$
c(t)+s(t)+\tilde{w}(t) n(t)+\tilde{T}_{1}(t) w_{1}(t)+\tilde{T}_{2}(t) w_{2}(t)=\bar{y}(t)
$$

where

$$
\tilde{w}(t) \equiv \bar{k}(t)+h w(t), \quad h \equiv \theta_{1} h_{1}+(1-\varphi) \theta_{2} h_{2} .
$$

The variable $\tilde{w}(t)$ is the opportunity cost of children fostering. 


\subsection{The utility and optimal behavior}

Following Zhang (2015), we assume that the utility is dependent on $c(t), s(t), \tilde{T}_{q}(t)$, and $n(t)$ as follows

$$
U(t)=c^{\xi_{0}(t)}(t) s^{\lambda_{0}(t)}(t) \tilde{T}_{1}^{\sigma_{01}(t)}(t) \tilde{T}_{2}^{\sigma_{02}(t)}(t) n^{v_{0}(t)}(t),
$$

where $\xi_{0}(t)>0$ is called the propensity to consume, $\lambda_{0}(t)>0$ the propensity to own wealth, $\sigma_{0 q}(t)>0$ the gender $q$ 's propensity to use leisure time, and $v_{0}(t)>0$ the propensity to have children. Maximizing $U(t)$ subject to (10) yields

$$
c(t)=\xi(t) \bar{y}(t), \quad s(t)=\lambda(t) \bar{y}(t), \quad \tilde{T}_{q}(t)=\frac{\sigma_{q}(t) \bar{y}(t)}{w_{q}(t)}, n(t)=\frac{v(t) \bar{y}(t)}{\tilde{w}(t)},
$$

where

$$
\begin{aligned}
& \xi(t) \equiv \xi_{0}(t) \rho(t), \lambda(t) \equiv \lambda_{0}(t) \rho(t), \tilde{T}_{q}(t) \equiv \sigma_{0 q}(t) \rho(t), \quad v(t) \equiv v_{0}(t) \rho(t), \\
& \rho(t) \equiv \frac{1}{\xi_{01}(t)+\lambda_{01}(t)+\sigma_{01}(t)+\sigma_{02}(t)+v_{0}(t)} .
\end{aligned}
$$

\subsection{The time preference and the propensity to hold wealth}

Following Zhang $(2012,2013)$, we now introduce preference changes. The modeling of the preference is strongly influenced by the literature of the neoclassical growth model with habit formation and preference change (e.g., Dornbusch and Frenkel, 1973; Persson and Svensson, 1985; Epstein, 1987; Chang et al. 2011; Blanchard and Fischer, 1989; Orphanides and Solow, 1990; Das, 2003; Smithin, 2004; Kam and Mohsin, 2006; and Hirose and lkeda, 2008). Zhang $(2012,2013)$ forms endogenous change in the propensity to save on the basis of the literature about growth and preference change. According to Zhang, the propensity to save adapts to the wealth, wage rates in the following way

$$
\lambda_{0}(t)=\bar{\lambda}+\lambda_{1} w_{1}(t)+\lambda_{2} w_{2}(t)
$$

where $\bar{\lambda}>0, \lambda_{1}$, and $\lambda_{2}$, are parameters. This is a simplified form the preference. For simplicity, the propensity to save is assumed to be proportional to the wealth, wage rates. When $\lambda_{w}=\lambda_{q}=0$, the propensity to hold wealth is constant. We don't specify the signs of $\lambda_{q}$ in this stage of the analysis because the propensity to save may be positively or negatively related to these variables.

\subsection{The habit formation for consumption and the propensity to consume consumer goods}

We now model endogenous change in the propensity to consume goods. We base the ideas of habit formation in the literature of economic growth (Deaton and Muellbauer, 1980; Carroll, 2000; Amano and Laubach, 2004; Alvarez-Cuadrado et al., 2004; Gómez, 2008; Corrado and Holly, 2011). We build the habit formation with regard to consumer goods as follows 


$$
\dot{\hbar}_{c}(t)=\hat{\xi}\left[c(t)-\hbar_{c}(t)\right]
$$

where $\hbar_{c}(t)$ is the stock of habit with regard to the consumption good. A larger value for $\hat{\xi}$ implies lower weights given to more distant values of the levels of consumption. The parameter measures the relative weights of consumption at different times. This formation is based on the internal habit formation in the literature. If the current consumption is higher than the level of the habit stock, then the level of habit stock tends to rise, and vice versa. Following Zhang (2012), we assume that the propensity to consume is a function of the wage incomes and the habit stock as follows

$$
\xi_{0}(t)=\bar{\xi}+\xi_{1} w_{1}(t)+\xi_{2} w_{2}(t)+\xi_{h} \hbar_{c}(t),
$$

where $\bar{\xi}>0, \xi_{q}$, and $\xi_{h} \geq 0$ are parameters. It is reasonable to assume that the birth and mortality rates will also affect the propensities to consume. As shown in the appendix, it is straightforward to take account of these factors. If $\xi_{q}=0$ and $\xi_{h}=0$, the propensity is constant. The term $\xi_{q} w_{q}(t)$ implies that the propensity to consume is affected by the wage rates. If $\xi_{w}>(<) 0$, then a rise in the wage rate raises (reduces) the propensity to consume. It is reasonable to assume $\xi_{w} \geq 0$, at least for normal goods. If the goods under consideration are inferior, the sign may be opposite. In reality, relations between wage and consumption are very complicated (e.g., Lusardi, 1996; Storesletten, et al. 2004; and Lise and Seitz, 2011). The term $\xi_{h} \hbar(t)$ implies that if the habit stock is increasing, the propensity to consume will rise, and vice versa.

\subsection{The habit formation for leisure times and the propensity to use leisure}

The change in the propensity to use leisure is similar to the change in the propensity to consume consumer goods. Similar to (14), the evolution of the habit stock for leisure time $\hbar_{h q}(t)$ is

$$
\dot{\hbar}_{h q}(t)=\hat{\sigma}_{q}\left[\widetilde{T}_{q}(t)-\hbar_{h q}(t)\right], \quad q=1,2,
$$

where $\hat{\sigma}_{q}$ is a non-negative parameter, measuring the relative weights of leisure time at different times. If the current leisure time is more than the level of the habit stock, the level of habit stock tends to rise, and vice versa. The propensities to use leisure time are specified as

$$
\sigma_{0 q}(t)=\bar{\sigma}_{q}+\sigma_{q 1} w_{1}(t)+\sigma_{q 2} w_{2}(t)+\tilde{\sigma}_{q 1} \hbar_{T 1}(t)+\tilde{\sigma}_{q 2} \hbar_{T 2}(t), q=1,2,
$$

where $\bar{\sigma}_{q}$ are positive parameters, and signs of the parameters $\sigma_{q j}$ and $\tilde{\sigma}_{q j}$ are ambiguous. The term $\sigma_{j q} w_{q}(t)$ implies that the propensity to use leisure time is affected by the wage rates. 


\subsection{The habit formation for having children and change in the propensity to have children}

The evolution of the habit stock for having children $\hbar_{b}(t)$ is

$$
\dot{\hbar}_{b}(t)=\hat{\sigma}_{b}\left[n(t)-\hbar_{b}(t)\right]
$$

where $\hat{\sigma}_{b}$ is a non-negative parameter, measuring the relative weights of birth rate at different times. The propensity to have children is specified as

$$
v_{0}(t)=\hat{v}+v_{1} w_{1}(t)+v_{2} w_{2}(t)+v_{b} \hbar_{b}(t)
$$

where the parameter $\hat{v}$ is positive and signs of $v_{q}$ and $v_{b}$ are ambiguous.

\subsection{The birth and mortality rates and population dynamics}

According to the definitions, the population change follows

$$
\dot{N}(t)=(n(t)-d(t)) N(t),
$$

where $n(t)$ and $d(t)$ are respectively the birth rate and mortality rate. The birth rate is given by (11). Influenced by different approaches in the literature of economic growth and population dynamics (e.g., Haavelmo, 1954; Razin and Ben-Zion, 1975; Stutzer, 1980; Yip and Zhang, 1997; Chu et al., 2012), Zhang assumes that the mortality rate is negatively related to the disposable income in the following way

$$
d(t)=\frac{\bar{v} N^{b}(t)}{\bar{y}^{a}(t)},
$$

where $\bar{v} \geq 0, a \geq 0$. We call $\bar{v}$ the mortality rate parameter. As in the Haavelmo model, an improvement in living conditions implies that people live longer. The term $N^{b}(t)$ takes account of possible influences of the population on mortality. Insert (11) and (20) in (19)

$$
\dot{N}(t)=\left(\frac{v \bar{y}(t)}{\tilde{w}(t)}-\frac{\bar{v} N^{b}(t)}{\bar{y}^{a}(t)}\right) N(t) .
$$

\subsection{Wealth dynamics}

We now find dynamics of wealth accumulation. According to the definition of $s(t)$, the change in the household's wealth is given by

$$
\dot{\bar{k}}(t)=s(t)-\bar{k}(t)=\lambda(t) \bar{y}(t)-\bar{k}(t) .
$$




\subsection{Demand for and supply of goods}

The national saving is the sum of the households' saving. As output of the capital goods sector is equal to the net savings and the depreciation of capital stock, we have

$$
S(t)+C(t)-K(t)+\delta_{k} K(t)=F(t),
$$

where $S(t)-K(t)+\delta_{k} K(t)$ is the sum of the net saving and depreciation and

$$
S(t)=s(t) N(t), C(t)=c(t) N(t), K(t)=\bar{k}(t) N(t) .
$$

We have thus built the dynamic model. It should be noted that the model is general in the sense that the Solow model and the Haavelmo model can be considered as special cases of our model. Moreover, as our model is based on some well-known growth models with habit formation and preference change and includes some features which no other single theoretical model explains, we should be able to explain some interactions which other formal models fail to explain. We now examine dynamics of the model.

\section{The dynamics and its properties}

This section examines dynamics of the model. First, we introduce $z(t) \equiv\left(r(t)+\delta_{k}\right) / w(t)$. We show that the dynamics can be expressed by six differential equations with $z(t), N(t)$, $\hbar_{c}(t), \hbar_{1}(t), \hbar_{2}(t)$, and $\hbar_{b}(t)$ as the variables.

\section{Lemma}

The dynamics of the economic system is governed by the six differential equations

$$
\begin{gathered}
\dot{z}=\tilde{\Omega}_{z}\left(z, \hbar_{c}, \hbar_{h 1}, \hbar_{h 2}, \hbar_{b}, N\right), \\
\dot{\hbar}_{c}=\tilde{\Omega}_{c}\left(z, \hbar_{c}, \hbar_{h 1}, \hbar_{h 2}, \hbar_{b}, N\right), \\
\dot{\hbar}_{T q}=\tilde{\Omega}_{q}\left(z, \hbar_{c}, \hbar_{h 1}, \hbar_{h 2}, \hbar_{b}, N\right), q=1,2, \\
\dot{\hbar}_{b}=\tilde{\Omega}_{b}\left(z, \hbar_{c}, \hbar_{h 1}, \hbar_{h 2}, \hbar_{b}, N\right), \\
\dot{N}=\tilde{\Omega}_{N}\left(z, \hbar_{c}, \hbar_{h 1}, \hbar_{h 2}, \hbar_{b}, N\right),
\end{gathered}
$$

where the functions $\tilde{\Omega}_{m}\left(z, \hbar_{c}, \hbar_{h 1}, \hbar_{h 2}, \hbar_{b}, N\right)$ are functions of $z(t), \hbar_{c}(t), \hbar_{h q}(t)$, $\hbar_{b}(t)$, and $N(t)$ defined in the Appendix. Moreover, all the other variables are determined as functions of $z(t), \hbar_{c}(t), \hbar_{h q}(t), \hbar_{b}(t)$, and $N(t): \bar{k}(t)$ by (A11) $\rightarrow r(t)$ and $w_{q}(t)$ by (A2) $\rightarrow \bar{y}(t)$ by (A3) $\rightarrow c(t), s(t), \tilde{T}_{q}(t)$, and $n(t)$ by (11) $\rightarrow \bar{T}_{q}(t)$ by (6) $\rightarrow T_{q}(t)$ by $(\mathrm{A} 4) \rightarrow \bar{N}(t)$ by (1) $\rightarrow K(t)$ by (A1) $\rightarrow F(t)$ by (2).

The differential equations system (24) has six variables. As demonstrated in the Appendix, the expressions are complicated. It is difficult to explicitly interpret economic implications of the six equations. For illustration, we simulate the model to illustrate behavior of the system. 
In the remainder of this study, we specify the depreciation rate by $\delta_{k}=0.05$, and let $T_{0}=24$. We specify the other parameters as follows

$$
\begin{aligned}
& \alpha=0.34, \lambda_{0}=0.6, \quad \xi_{0}=0.2, \quad v_{0}=0.4, \sigma_{10}=0.15, \quad \sigma_{10}=0.15, A=1, \\
& a=0.3, b=0.3, \quad h_{1}=3, \quad h_{2}=2.4, \theta_{1}=2, \theta_{2}=5, \quad \bar{v}=1, \bar{\lambda}=0.6, \\
& \lambda_{1}=\lambda_{2}=-0.01, \quad \bar{\sigma}_{1}=0.15, \quad \bar{\sigma}_{2}=0.16, \\
& \sigma_{11}=\sigma_{21}=\tilde{\sigma}_{11}=\tilde{\sigma}_{22}=0.001, \quad \sigma_{12}=\sigma_{22}=\tilde{\sigma}_{12}=\tilde{\sigma}_{21}=-0.001, \bar{\xi}=0.2, \\
& \xi_{1}=\xi_{2}=\xi_{h}=0.001, \bar{v}=0.4, \quad v_{1}=v_{2}=v_{b}=0.001, \quad \hat{\xi}=\hat{\sigma}_{1}=\hat{\sigma}_{2}=\hat{\sigma}_{b}=0.4 .
\end{aligned}
$$

The total productivity and the output elasticity of the production sector are respectively 1 and 0.34 . It should be noted that both in theoretical simulations and empirical studies the output elasticity of capital in the Cobb-Douglas production is often valued approximately equal to 0.3 and the value of the total productivity is chosen to be close to unity (e.g., Miles and Scott, 2005; Abel et al, 2007). Although the chosen values of the preference parameters are not empirically based, we choose the coefficients associated with the wage and wealth very small so that we may effectively analyze the effects of changes in these coefficients on the economic structure. To follow the motion of the system, we specify the initial conditions

$$
z(0)=1.9, \quad N(0)=30, \hbar_{c}(0)=21, \hbar_{h 1}(0)=11, \hbar_{h 2}(0)=16.5, \hbar_{b}(0)=0.58 .
$$

The simulation result is plotted in Figure 1. The population rises from its low initial condition. The birth rate falls and mortality rate rises over the simulation period. The initial value of the habit stock of birth rate is much lower than the birth rate. The low habit stock reduces the birth rate. The wealth and opportunity cost of children rise. The labor force, total capital and output are increased. The wage rates are enhanced and rate of interest is reduced. The falling in birth rate is associated with falling in both man's and woman's time of children fostering. Both men and women work less hours and have more leisure hours. Both consumption level and habit stock of consumption level are augmented. The (relative) propensity to save falls. The father's (mother's) propensity to have leisure rises (falls). The propensity to have children falls. 

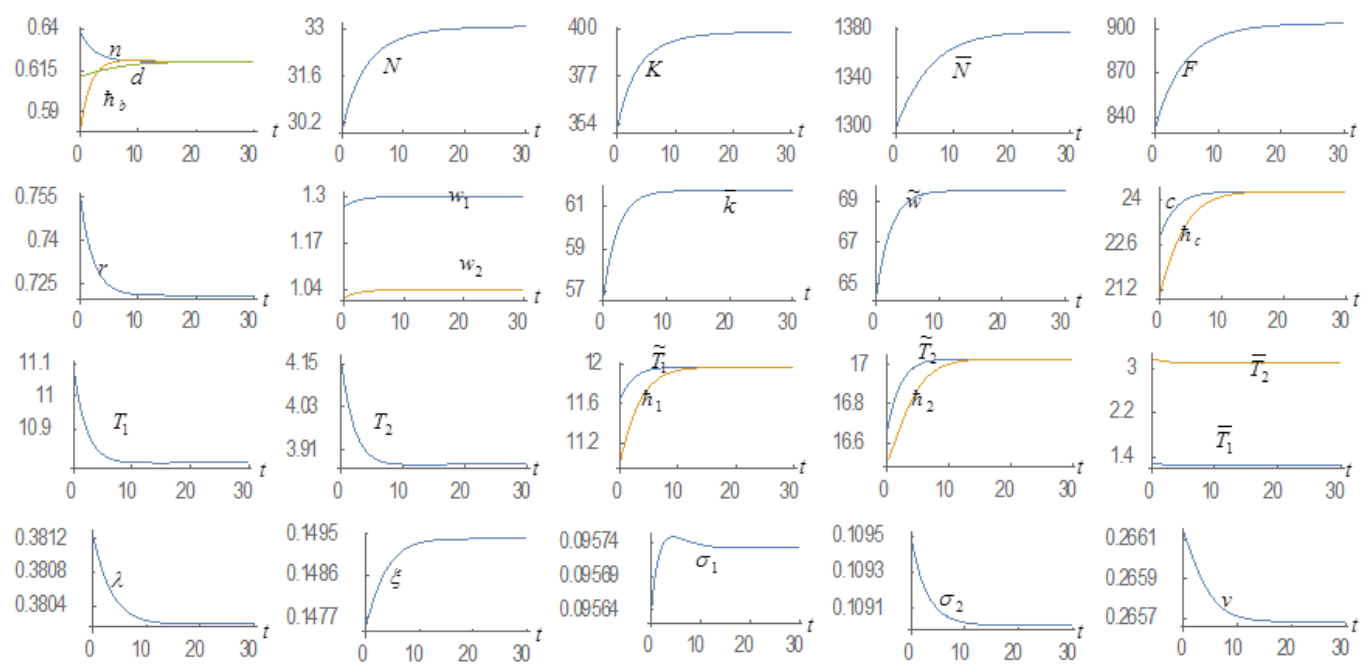

Figure 1: The Motion of the Economic System

It is straightforward to confirm that all the variables become stationary in the long term. This implies the existence of an equilibrium point. The simulation confirms that the system has an equilibrium point. We list the equilibrium values of the variables as follows

$$
\begin{aligned}
& N=33.06, K=398.5, \bar{N}=1377.8, F=903.7, n=\hbar_{b}=d=0.62, \quad r=0.72, \\
& w_{1}=1.3, \quad w_{2}=1.04, \quad \tilde{w}=69.5, \bar{k}=61.7, T_{1}=10.8, T_{2}=3.87, \\
& \tilde{T}_{1}=\hbar_{h 1}=11.96, \tilde{T}_{2}=\hbar_{h 2}=17.03, \bar{T}_{1}=1.24, \bar{T}_{2}=3.1, \quad c=\hbar_{c}=24.25, \\
& \lambda=0.38, \quad \xi=0.15, \sigma_{1}=0.096, \sigma_{2}=0.109, \quad v=0.266
\end{aligned}
$$

We calculate the six eigenvalues:

$$
-0.4,-0.3998,-0.387,-0.387 \pm 0.06,-0.326,-0.186 \text {. }
$$

As the six eigenvalues are negative, the equilibrium point is locally stable. Hence, the system always approaches its equilibrium point if it is not far from the equilibrium point.

\section{Comparative dynamic analysis}

We simulated the motion of the national economy. We now examine how the economic system reacts to some exogenous changes. As the lemma provides the computational procedure to calibrate the motion of all the variables, it is straightforward to examine effects of change in any parameter on transitory processes as well stationary states of all the variables. We use a variable $\bar{\Delta} x(t)$ to stand for the change rate of the variable $x(t)$ in percentage due to changes in the parameter value.

\subsection{More weights being given to the habit stock of children}

Values of children for parents are changeable due to so many possible factors such as economic conditions and cultural values, social customs, and traditions. We assume that the 
propensity to have children is affected by the habit stock of children. We now study how the economic system will be affected if more weight is given to the habit stock of children is the following way: $v_{b}: 0.001 \Rightarrow 0.01$. The simulation result is plotted in Figure 2 . The propensity to have children is enhanced as people weigh more on the family size in the past. It should be noted that in modern developed economies $v_{b}$ seems to be declining. As more weight is given to the habit stock of children, the population increased. The birth rate, the habit stock of birth rate and the mortality rate are enhanced. The labor force and national output falls initially and rises in the long term. The rate of interest rises and the wage rates are reduced. The household wealth, consumption level, and opportunity cost of children fostering rise initially and fall in the long term. The parents work less hours and spend more time on taking care of children. The leisure times rise initially and fall in the long term. The propensities to save and to consume fall. The father's and mother's propensities to have leisure fall. The propensity to have children rises.
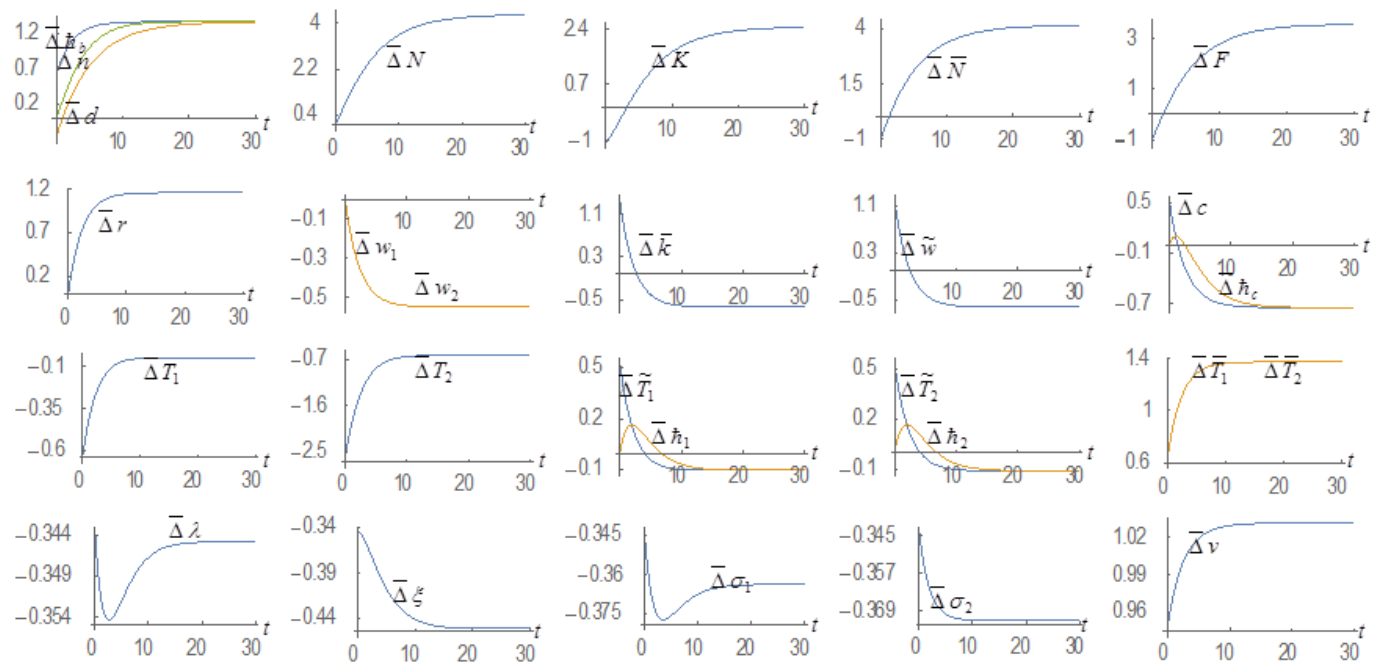

Figure 2: More Weights Being Given to the Habit Stock of Children

\subsection{The wife's wage rate having negative impact on the propensity to have children}

As the woman's social status and attitudes toward work and children are changed, the family's propensity for children may be influenced. We now allow the wife's wage to have negative impact on the propensity to have children in the following way: $v_{2}: 0.001 \Rightarrow-0.005$. This implies that a rise in the mother's wage rate reduces the propensity to have children. The simulation result is plotted in Figure 3 . The birth and mortality rates and the population fall. The labor force, national capital stock and national product rise initially and fall in the long term. The rate of interest falls and the wage rates rise. The household wealth, opportunity cost of children fostering, and consumption level fall initially and rise in the long term. The parents increase work hours and reduce hours of children fostering. The parents initially spend less leisure time and more leisure time in the long term. The propensities to save and to consume are enhanced. The father's and mother's propensities to have leisure fall. The propensity to have children falls. 

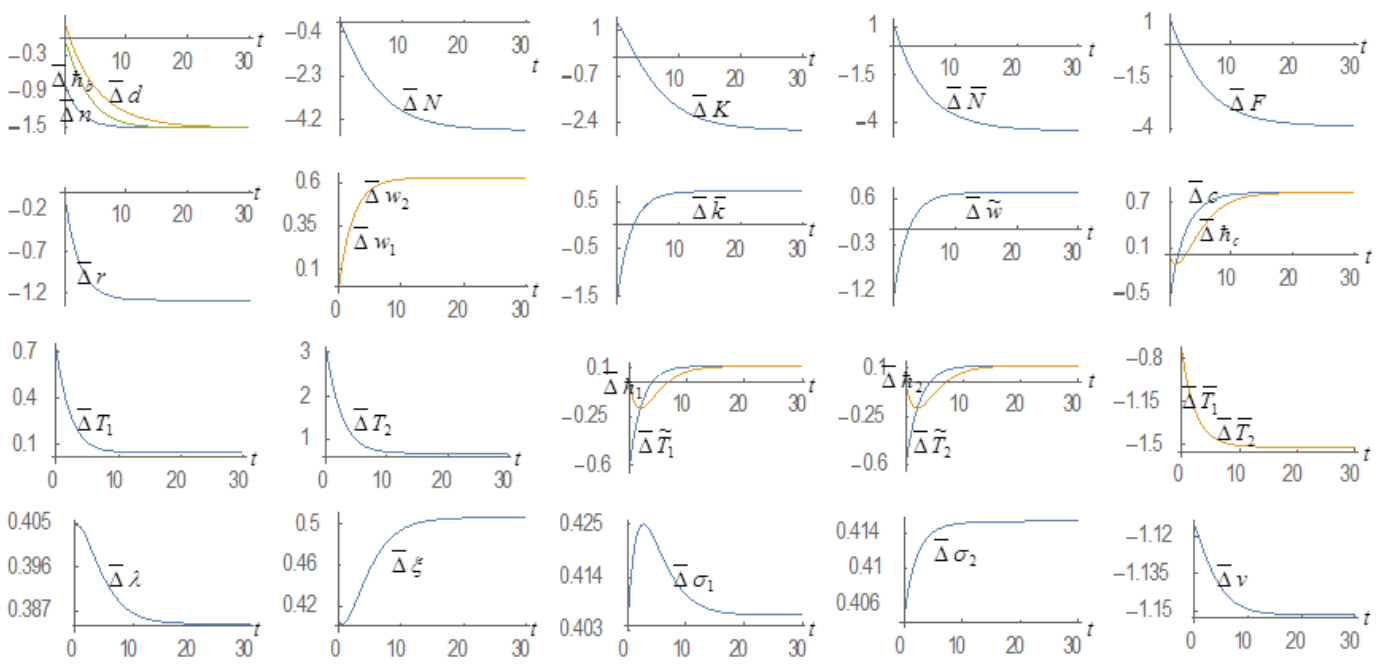

Figure 3: The Wife's Wage Rate Reducing the Propensity to Have Children

\subsection{The wife weighing less the habit stock of leisure time}

We now study how the national economy and household behavior are affected if women weigh more the habit stock of leisure time in the following way: $\tilde{\sigma}_{22}: 0.001 \Rightarrow-0.001$. The simulation result is plotted in Figure 4. This implies that the mother's habit stock of leisure time has negative impact on the propensity to use leisure time. The birth rate rises. The mortality rate falls initially and rises in the long term. The population, the labor force, national capital stock and national product are enhanced. The rate of interest rises and the wage rates fall. The household wealth, opportunity cost of children fostering, and consumption level are enhanced. The husband works less hours and spends more time on leisure and the wife works more hours and reduces leisure time. The parents initially spend more hours on taking care of children. The propensities to save and to consume are enhanced. The father's and mother's propensities to have leisure fall. The propensity to have children rises.
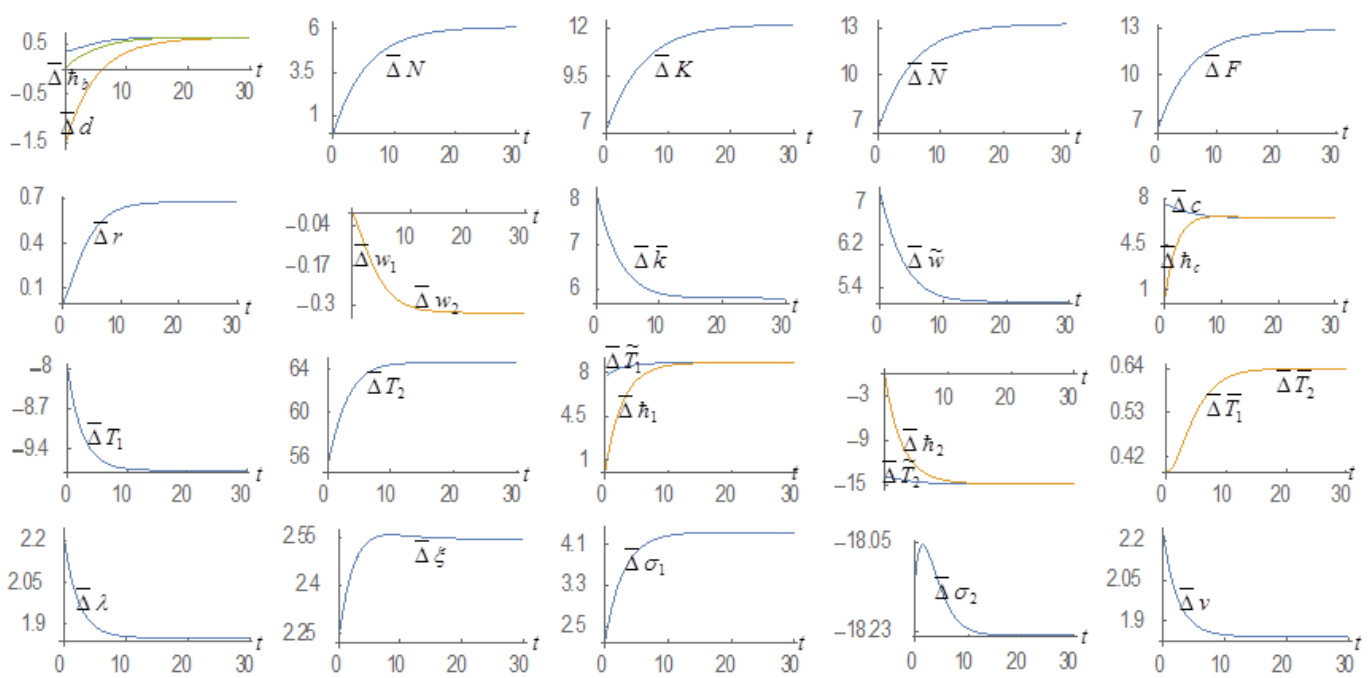

Figure 4: The Wife Weighing Less the Habit Stock of Leisure Time 


\subsection{The wife's habit stock of leisure time having negative impact on the husband's propensity to use leisure time}

We now study how the national economy and household behavior are affected if women weigh more the habit stock of leisure time in the following way: $\tilde{\sigma}_{12}:-0.001 \Rightarrow 0.003$. The simulation result is plotted in Figure 5 . The birth rate rises. The mortality rate falls initially and rises in the long term. The population, the labor force, national capital stock and national product are reduced. The rate of interest falls and the wage rates are enhanced. The household wealth, opportunity cost of children fostering, and consumption level are reduced. The husband works less hours and spends more time on leisure and the wife works more hours and reduces leisure time. The parents reduce hours on taking care of children. The propensities to save and to consume are lowered. The father's propensity to have leisure rises and mother's propensity to have leisure falls. The propensity to have children falls.
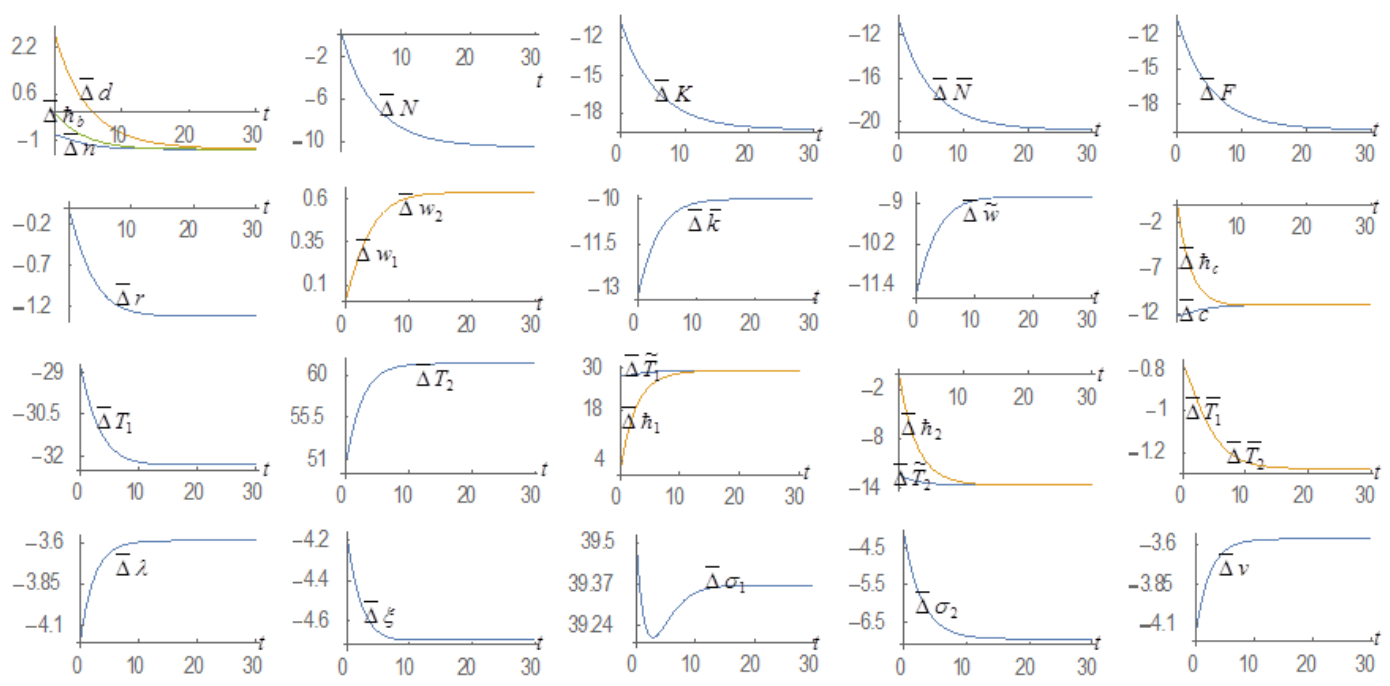

Figure 5: The Wife's Habit Stock of Leisure Time Having Negative Impact

\subsection{The wife's wage rate having negative impact on the husband's propensity to use leisure time}

We now study how the national economy and household behavior are affected if the wife's wage rate has negative impact on the husband's propensity to use leisure time as follows: $\sigma_{12}:-0.001 \Rightarrow 0.003$. The simulation result is plotted in Figure 6 . The birth rate falls. The mortality rate rises initially and rises in the long term. The population, the labor force, national capital stock and national product are reduced. The rate of interest falls and the wage rates are enhanced. The household wealth, opportunity cost of children fostering, and consumption level are reduced. The husband works less hours and spends more time on leisure and the wife works more hours and reduces leisure time. The parents reduce hours on taking care of children. The propensities to save and to consume are lowered. The father's propensity to have leisure rises and mother's propensity to have leisure falls. The propensity to have children falls. 


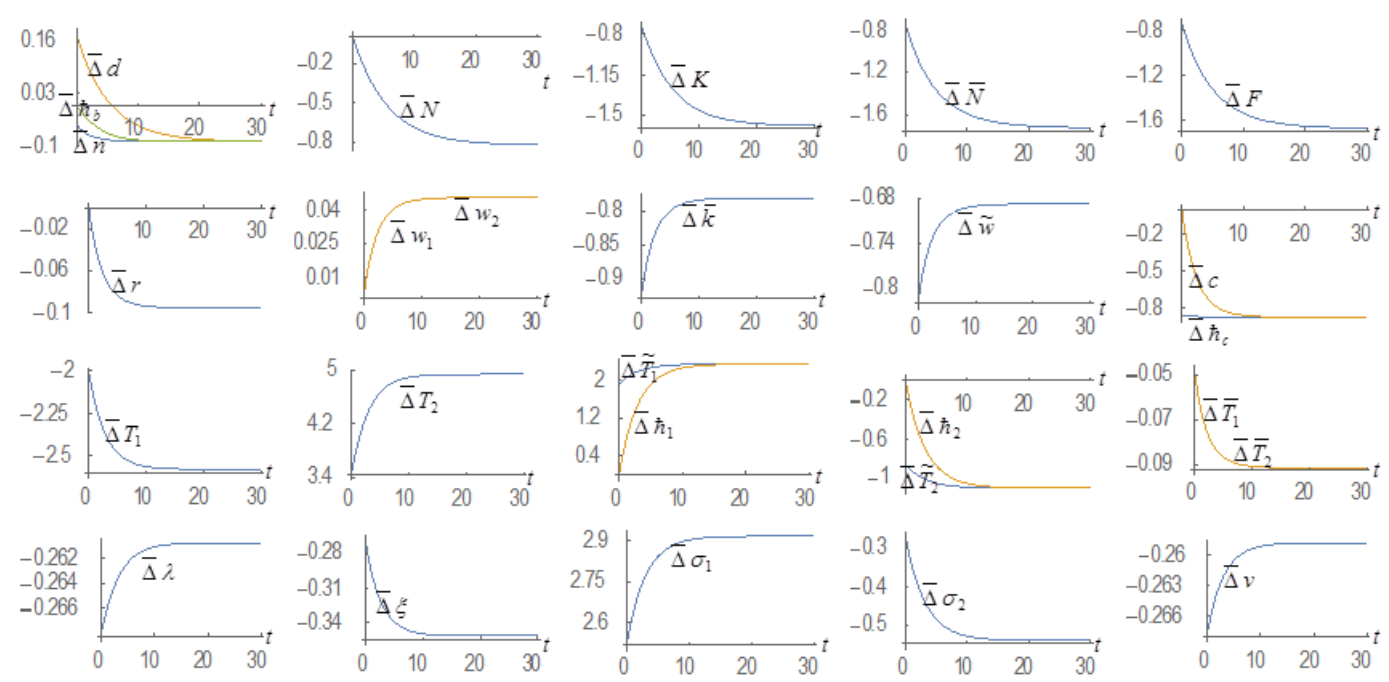

Figure 6: The Wife's Wage Rate Having Negative Impact on the Husband's Propensity to Use Leisure Time

\subsection{Woman's human capital being improved}

We now enhance the mother's human capital as follows: $h_{2}: 2.4 \Rightarrow 2.6$. The results are plotted in Figure 7. As the mother accumulates more human capital, her wage income is increased. As the mother earns more per unit time, she works more and has less leisure time. The opportunity cost of child fostering is increased in association with the mother's wage rising. The father's wage is slightly affected. The father works less and stays longer at home. Both the mother and father shorten time of children fostering. The family consumes more and has more wealth. The capital, total labor input and output are increased. The mortality rate falls in association with improved living conditions. The net impact of falling birth and mortality rates increases the population. The propensity to save is reduced and the propensity to consume is enhanced. The man's propensity to use leisure time is increased and woman's propensity to use leisure time is reduced. The propensity to have children is increased.
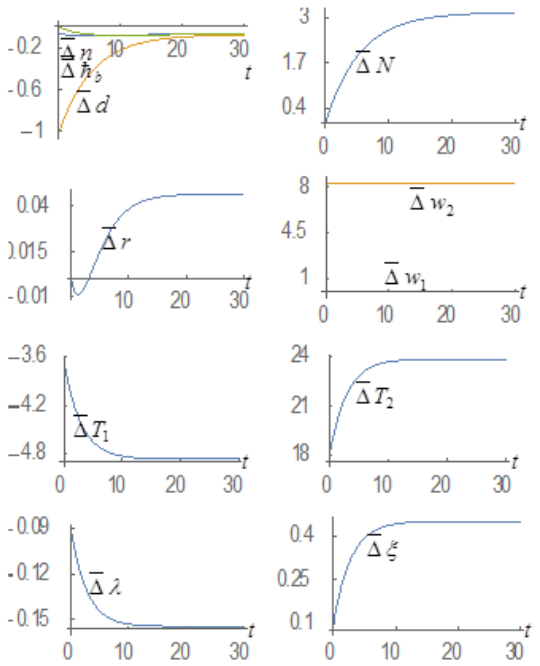
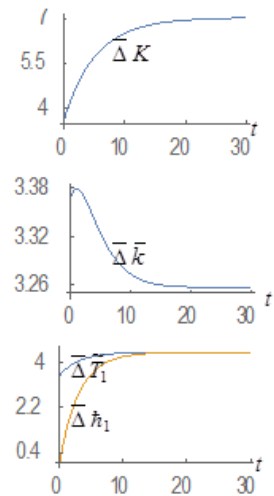
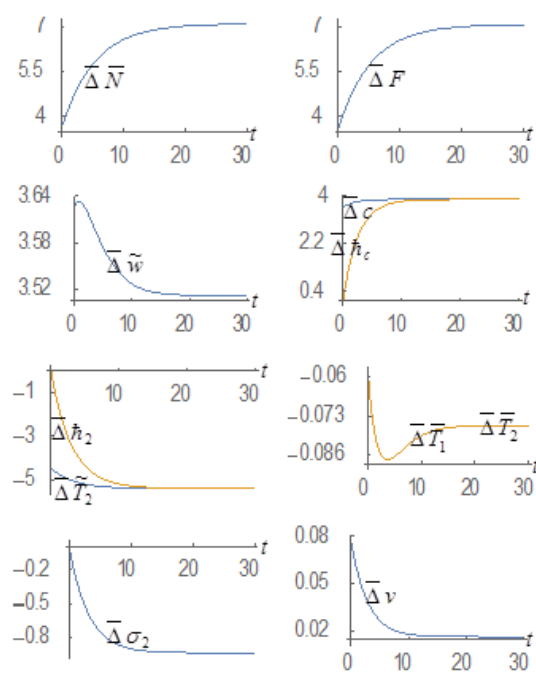

Figure 7: Woman's Human Capital Being Improved 


\subsection{A rise in the total factor productivity}

We now allow the total factor productivity to be increased as follows: $A: 1 \Rightarrow 1.05$. An immediate consequence of the change enhances the output level and wage rates. The household wealth and opportunity cost fall initially and increase in the long term. The birth rate is increased. The mortality rate is reduced initially and enhanced in the long term. Both the man and woman work more hours. They spend less leisure hours and more hours on children caring. The national wealth, the population, the labor input, and national output are augmented. The propensity to save falls. The propensities to consume and to have children are enhanced. The propensities to have leisure rise initially and fall in the long term.
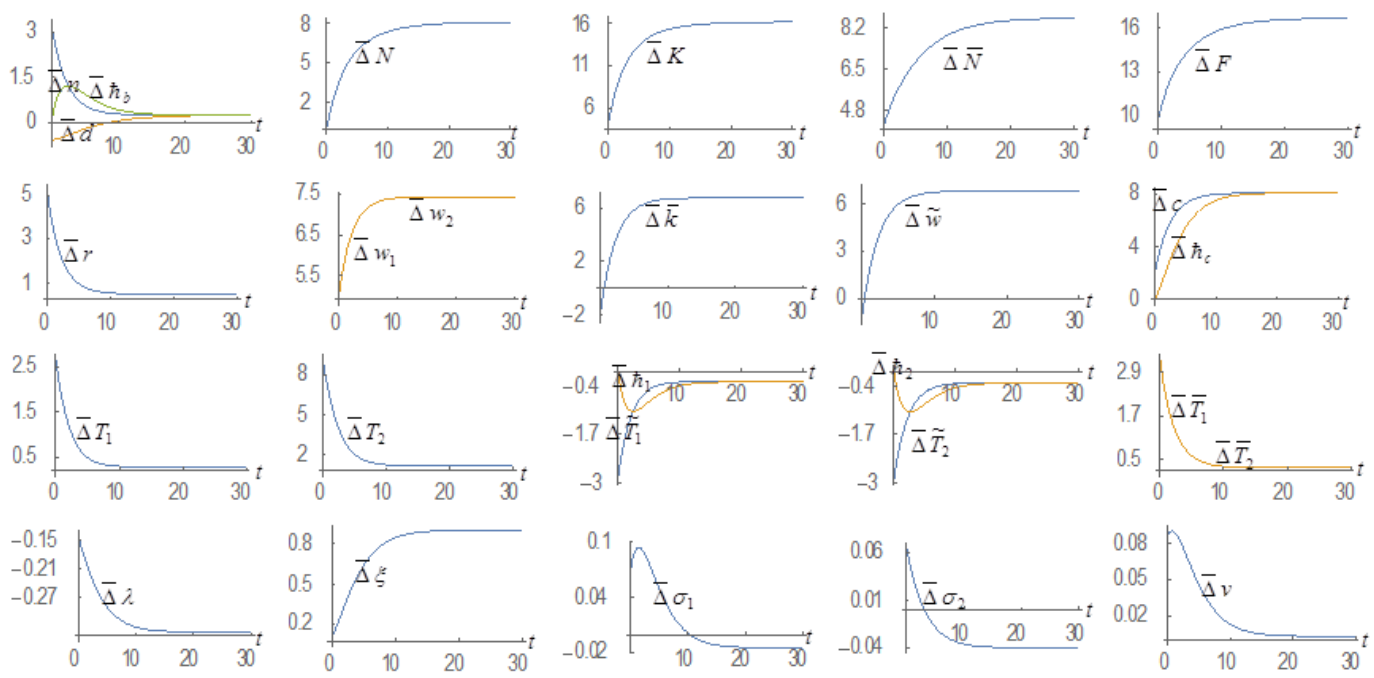

Figure 8: A Rise in the Total Factor Productivity

\subsection{The mother spending more time on each child fostering}

We now consider that the mother spends more hours with each child as follows: $\theta_{2}: 5 \Rightarrow 5.5$. The father's time on children caring is slightly reduced and the mother's time is increased. Both the father and the mother spend less time on leisure. The mother works more hours and the father works less hours. The mother spends more time on child fostering and the father spends less time on child fostering. The wage rates are enhanced. The opportunity cost of children fostering falls initially and is increased in the long term. The household wealth is reduced. The population and the mortality rate fall. The rate of interest falls. The total wealth, total labor input and output are all reduced. The family consumes less. 

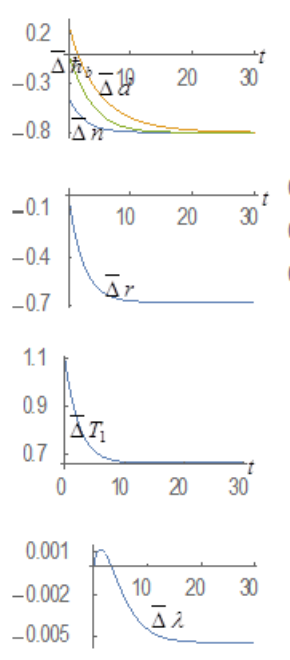
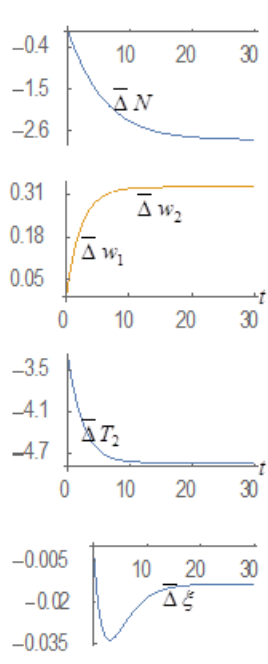
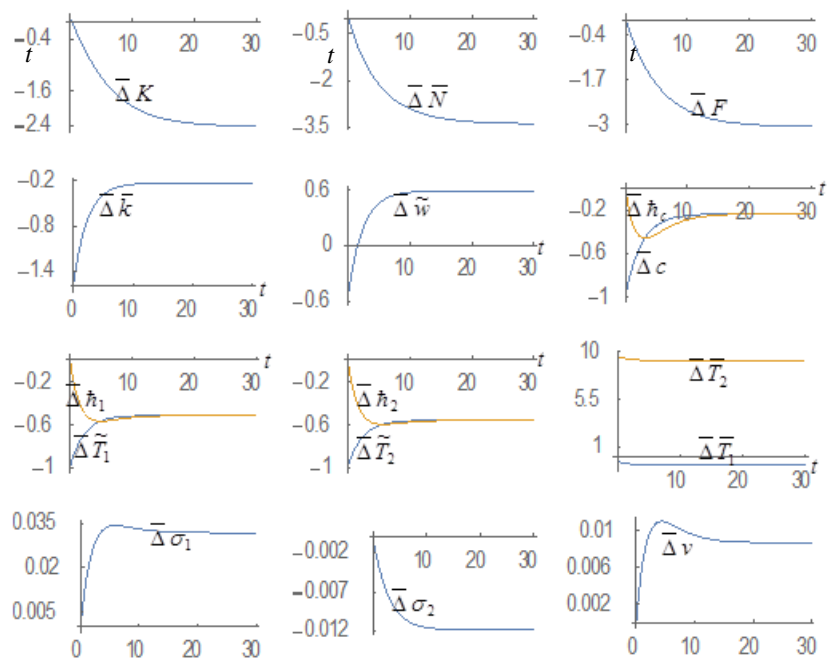

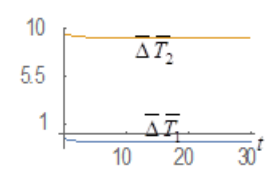

$-0.002$

$-0.007$

$-0.012$

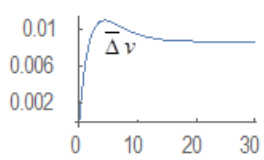

Figure 9: The Mother Spending More Time on Each Child Fostering

\section{In conclusion}

This study is concerned with economic growth and population change with habit formation and preference change within the analytical framework of the Solow one sector growth model. The study built a model of dynamic interactions between the birth rate, the mortality rate, the population, wealth accumulation, time distribution between work, leisure and children caring, habit formation and preference change. The production technology and markets were built on the Solow growth model. We based our modeling the population dynamics on the Haavelmo population model and the Barro-Becker fertility choice model. This study also took account of habit formation and preference change. Although it is influenced by the Ramsey growth theory with time preference and habit formation, it used Zhang's approach to the household with habit formation and preference change (Zhang, 2012, 2013). The study focuses on interactions among capital accumulation, economic structure, labor and capital distribution, habit formation and time preference in an integrated framework. We synthesized these dynamic forces in a compact framework, using the utility function proposed by Zhang. Analytically, we focus on transitional processes as well as economic equilibrium. As the economic system is given by autonomous nonlinear differential equations, it is not easy to analyze its behavior. We simulated the model to demonstrate the existence of an equilibrium point and motion of the dynamic system. We also examined the effects of changes in weights given to the habit stock of children, the wife's wage rate having negative impact on the propensity to have children, the wife weighing less the habit stock of leisure time, the wife's habit stock of leisure time having negative impact on the husband's propensity to use leisure time, the wife's wage rate having negative impact on the husband's propensity to use leisure time, woman's human capital being improved, a rise in the total factor productivity, and the mother spending more time on each child fostering. Our comparative dynamic analysis provides some insights into the complexity of dynamic processes of economic changes. For instance, when more weight is given to the habit stock of children, the propensity to have children is enhanced the population is increased; the birth rate, the habit stock of birth rate and the mortality rate are enhanced; the labor force and national output falls initially and rises in the long term; the rate of interest rises and the wage rates are reduced; the household wealth, consumption level, and opportunity cost of children fostering rise initially and fall in the long term; the parents work less hours and spend more time on taking care of children; the leisure times rise initially and fall in the long term; the 
propensities to save and to consume fall, the father's and mother's propensities to have leisure fall; and the propensity to have children rises. There are many ways to generalize and extend our model. An obvious limitation of our model is that children caring function exhibits constant return to scale in the parent's time spent on children caring. It is possible to generalize our model by applying more general production or utility functions. Our research may also be extended and generalized to study some observed phenomena related to gender, human capital and economic development.

\section{Appendix: Proving the lemma}

We now show that the dynamics can be expressed by differential equations. From (3), we get

$$
z \equiv \frac{r+\delta_{k}}{w}=\frac{\tilde{\alpha} \bar{N}}{K}
$$

where $\tilde{\alpha} \equiv \alpha / \beta$. Insert (A1) in (2) and (3)

$$
r=\alpha A\left(\frac{z}{\tilde{\alpha}}\right)^{\beta}-\delta_{k}, \quad w=\beta A\left(\frac{\tilde{\alpha}}{z}\right)^{\alpha}, w_{1}=w h_{1}, \quad w_{2}=w h_{2}
$$

We treat $r, w$ and $w_{q}$ as functions of $z$. From the definition of $\bar{y}$ and (3) we have

$$
\bar{y}=(1+r) \bar{k}+h_{0} w,
$$

were $h_{0} \equiv\left(h_{1}+h_{2}\right) T_{0}$. Use (8) and (11)

$$
T_{q}=T_{0}-\bar{T}_{q}-\tilde{T}_{q}=T_{0}-\left(\frac{\theta_{q} v}{\tilde{w}}+\frac{\sigma_{q}}{w_{q}}\right) \bar{y}
$$

Insert (A3) in (A4)

$$
T_{q}=\chi_{q}-\frac{\tilde{r}_{q} \bar{k}+\bar{r}_{q}}{\tilde{w}}-r_{q} \bar{k}
$$

where

$$
\chi_{q}=T_{0}-\frac{h_{0} w \sigma_{q}}{w_{q}}, \quad \tilde{r}_{q} \equiv \theta_{q} v(1+r), \quad \bar{r}_{q} \equiv h_{0} \theta_{q} v w, r_{q} \equiv \frac{(1+r) \sigma_{q}}{w_{q}}
$$

Insert (A5) in (1)

$$
\frac{\bar{N}}{N}=h_{1} T_{1}+h_{2} T_{2}=\chi-\frac{\tilde{r} \bar{k}+\bar{h}_{0}}{\tilde{w}}-\tilde{r}_{0} \bar{k}
$$


where

$$
\chi \equiv h_{1} \chi_{1}+h_{2} \chi_{2}, \quad \tilde{r} \equiv h_{1} \tilde{r}_{1}+h_{2} \tilde{r}_{2}, \bar{h}_{0} \equiv h_{1} \bar{r}_{1}+h_{2} \bar{r}_{2}, \quad \tilde{r}_{0} \equiv h_{1} r_{1}+h_{2} r_{2}
$$

From (16) we have

$$
\bar{\lambda} \bar{y}-\delta \bar{k}=\frac{F}{N}
$$

where $\bar{\lambda} \equiv \lambda+\xi$ and $\delta \equiv 1-\delta_{k}$. Insert (A3) and (3) in (A7)

$$
(\bar{\lambda}+\bar{\lambda} r-\delta) \bar{k}+\bar{\lambda} h_{0} w=\frac{w \bar{N}}{N \beta}
$$

Insert (A6) in (A8)

$$
\left(\frac{(\bar{\lambda}+\bar{\lambda} r-\delta) \beta}{w}+\tilde{r}_{0}\right) \bar{k}+\frac{\tilde{r} \bar{k}+\bar{h}_{0}}{\tilde{w}}+\beta \bar{\lambda} h_{0}-\chi=0 .
$$

From $\tilde{w}=\bar{k}+h w$ and (A9), we have

$$
\bar{k}^{2}+\tilde{m}_{1} \bar{k}+\tilde{m}_{2}=0
$$

where

$$
\begin{aligned}
& \tilde{m}_{1}\left(z, \hbar_{c}, \hbar_{h 1}, \hbar_{h 2}, \hbar_{b}, \bar{k}\right) \equiv \frac{(\bar{\lambda}+\bar{\lambda} r-\delta) h \beta+\tilde{r}_{0} h w+\beta \bar{\lambda} h_{0}-\chi+\tilde{r}}{\tilde{m}}, \\
& \tilde{m}_{2}\left(z, \hbar_{c}, \hbar_{h 1}, \hbar_{h 2}, \hbar_{b}, \bar{k}\right) \equiv \frac{\bar{h}_{0}+\left(\beta \bar{\lambda} h_{0}-\chi\right) h w}{\tilde{m}}, \\
& \tilde{m}\left(z, \hbar_{c}, \hbar_{h 1}, \hbar_{h 2}, \hbar_{b}, \bar{k}\right) \equiv \frac{(\bar{\lambda}+\bar{\lambda} r-\delta) \beta}{w}+\tilde{r}_{0} .
\end{aligned}
$$

Under this requirement it is straightforward to see that $\tilde{m}_{1}, \tilde{m}_{2}$, and $\tilde{m}$ are independent of $\bar{k}$. We solve (A10), treating $\bar{k}$ as the variable

$$
\bar{k}=\Omega\left(z, \hbar_{c}, \hbar_{h 1}, \hbar_{h 2}, \hbar_{b}, N\right) \equiv \frac{-\tilde{m}_{1} \pm \sqrt{\tilde{m}_{1}^{2}-4 \tilde{m}_{2}}}{2} .
$$


From (A11) we determine $\bar{k}$ as a function of $z, \hbar_{c}, \hbar_{h q}$, and $\hbar_{b}$. We follow the following procedure to determine the variables as functions $z, \hbar_{c}, \hbar_{h q}, \hbar_{b}$, and $N: \bar{k}$ by (A11) $\rightarrow$ $r$ and $w_{q}$ by (A2) $\rightarrow \bar{y}$ by (A3) $\rightarrow c, s, \tilde{T}_{q}$, and $n$ by (11) $\rightarrow \bar{T}_{q}$ by (6) $\rightarrow T_{q}$ by (A4)

$\rightarrow \bar{N}$ by (1) $\rightarrow K$ by (A1) $\rightarrow F$ by (2). From this procedure, (13), (15), (17), (21), and (22), we have

$$
\begin{array}{r}
\dot{\hbar}_{c}=\tilde{\Omega}_{c}\left(z, \hbar_{c}, \hbar_{h 1}, \hbar_{h 2}, \hbar_{b}, N\right), \\
\dot{\hbar}_{T q}=\tilde{\Omega}_{q}\left(z, \hbar_{c}, \hbar_{h 1}, \hbar_{h 2}, \hbar_{b}, N\right), \\
\dot{\hbar}_{b}=\tilde{\Omega}_{b}\left(z, \hbar_{c}, \hbar_{h 1}, \hbar_{h 2}, \hbar_{b}, N\right), \\
\dot{N}=\tilde{\Omega}_{N}\left(z, \hbar_{c}, \hbar_{h 1}, \hbar_{h 2}, \hbar_{b}, N\right), \\
\dot{\bar{k}}=\tilde{\Omega}_{k}\left(z, \hbar_{c}, \hbar_{h 1}, \hbar_{h 2}, \hbar_{b}, N\right) .
\end{array}
$$

We don't provide explicit expressions of the above equations as the expressions are tedious. From (A11), we have

$$
\dot{\bar{k}}=\frac{\partial \Omega}{\partial z} \dot{z}+\frac{\partial \Omega}{\partial \hbar_{c}} \dot{\hbar}_{c}+\frac{\partial \Omega}{\partial \hbar_{h 1}} \dot{\hbar}_{h 1}+\frac{\partial \Omega}{\partial \hbar_{h 2}} \dot{\hbar}_{h 2}+\frac{\partial \Omega}{\partial \hbar_{b}} \dot{\hbar}_{b}+\frac{\partial \Omega}{\partial N} \dot{N} .
$$

Insert (A12) in (A14)

$$
\dot{\bar{k}}=\frac{\partial \Omega}{\partial z} \dot{z}+\tilde{\Omega}_{c} \frac{\partial \Omega}{\partial \hbar_{c}}+\tilde{\Omega}_{1} \frac{\partial \Omega}{\partial \hbar_{h 1}}+\tilde{\Omega}_{2} \frac{\partial \Omega}{\partial \hbar_{h 2}}+\tilde{\Omega}_{b} \frac{\partial \Omega}{\partial \hbar_{b}}+\tilde{\Omega}_{N} \frac{\partial \Omega}{\partial N} .
$$

From (A13) and (A15) we solve

$$
\begin{aligned}
\dot{z} & =\tilde{\Omega}_{z}\left(z, \hbar_{c}, \hbar_{h 1}, \hbar_{h 2}, \hbar_{b}, N\right) \\
& \equiv\left(\tilde{\Omega}_{k}-\tilde{\Omega}_{c} \frac{\partial \Omega}{\partial \hbar_{c}}-\tilde{\Omega}_{1} \frac{\partial \Omega}{\partial \hbar_{h 1}}-\tilde{\Omega}_{2} \frac{\partial \Omega}{\partial \hbar_{h 2}}-\tilde{\Omega}_{b} \frac{\partial \Omega}{\partial \hbar_{b}}-\tilde{\Omega}_{N} \frac{\partial \Omega}{\partial N}\right)\left(\frac{\partial \Omega}{\partial z}\right)^{-1} .
\end{aligned}
$$

We thus proved the lemma.

\section{Acknowledgements}

The author is grateful to the constructive comments of the two anonymous referees. The author is also grateful for the financial support from the Grants-in-Aid for Scientific Research (C), Project No. 25380246, Japan Society for the Promotion of Science. 


\section{References}

Abel, A. (1990). 'Asset Prices under Habit Formation and Catching up with the Joneses', American Economic Review, vol. 80, pp. 38-42.

Abel, A., Bernanke, B.S., and Croushore, D. (2007). Macroeconomics, New Jersey: Prentice Hall. Adsera, A. (2005). „Vanishing Children: From High Unemployment to Low Fertility in Developed Countries", American Economic Review, vol. 95, pp. 189-93.

Albanesi, S. and Olivetti, C. (2009). 'Home Production, Market Production and the Gender Wage Gap: Incentives and Expectations', Review of Economic Dynamics, vol. 12, pp. 80-107.

Alvarez-Cuadrado, F., Monteriro, G., and Turnovsky, S.J. (2004). 'Habit Formation, Catching-Up with the Joneses, and Economic Growth', Journal of Economic Growth, vol. 9, pp. 47-80.

Amano, J.D. and Laubach, T. (2004). 'Implication of Habit Formation for Optimal Monetary Policy', Journal of Monetay Economics, vol. 51, pp. 305-25.

Azariadis, C. (1993) Intertemporal Macroeconomics, Oxford: Blackwell.

Balestra, C. and Dottori, D. (2012). 'Aging Society, Health and the Environment', Journal of Population Economics, vol. 25, pp. 1045-76.

Barro, R.J. and Becker, G.S. (1989). 'Fertility Choice in a Model of Economic Growth', Econometrica, vol. 57, pp. 481-501.

Barro, R.J. and X. Sala-i-Martin (1995). Economic Growth, New York: McGraw-Hill, Inc.

Becker, G. S. (1981). A Treatise on the Family, Cambridge, MA: Harvard University Press.

Becker, G. S. (1992). Habits, 'Addictions and Traditions', Kyklos, vol. 45, pp. 327-45.

Becker, G.S. and Mulligan, C.B. (1997). 'The Endogenous Determination of Time Preference', The Quarterly Journal of Economics, vol. 112, pp. 729-58.

Becker, G., Murphy, K. M., and Tamura, R. (1990). 'Human Capital, Fertility, and Economic Growth', Journal of Political Economy, vol. 98, pp. 12-37.

Bhattacharya, J. and Qiao, X. (2007). 'Public and Private Expenditures on Health in a Growth Model', Journal of Economic Dynamics and Control, vol. 31, 2519-535.

Blackburn, K. and Cipriani, G.P. (2005). 'A Model of Longevity, Fertility and Growth', Journal of Economic Dynamics \& Control, vol. 26, pp.187-204.

Blanchard, O.J. and Fischer, S. (1989). Lectures on Macroeconomics, Cambridge, MA: MIT Press.

Boldrin, M., Christiano, L., and Fisher, J. (2001). 'Habit Persistence, Asset Returns, and the Business Cycle', American Economic Review, vol. 91, pp. 149-66.

Bosi, S. and Seegmuller, T. (2012). 'Mortality Differential and Growth: What Do We Learn from the Barro-Becker Model?', Mathematical Population Studies, vol. 19, pp. 27-50.

Burmeister, E. and Dobell, A.R. (1970). Mathematical Theories of Economic Growth, London: Collier Macmillan Publishers.

Campbell, J. and Cochrane, J. (1999). 'By Force of Habit: A Consumption-Based Explanation of Aggregate Stock Market Behavior', Journal of Political Economy, vol. 107, pp. 205-51.

Carroll, C.D. (2000). 'Solving Consumption Models with Multiplicative Habits', Economics Letters, vol. 68, pp. 67-77.

Chakraborty, S. (2004). 'Endogenous Lifetime and Economic Growth', Journal of Economic Theory vol. 116, pp. 119-37.

Chang, W.Y. Tsai, H.F., and Chang, J.J. (2011). 'Endogenous Time Preference, Interest-Rate Rules, and Indeterminacy', The Japanese Economic Review, vol. 62, pp. 348-64.

Chao, L.W., Szrek, H., Pereira, N.S., and Paul, M. (2009). 'Time Preference and Its Relationship with Age, Health, and Survival Probability', Judgment and Decision Making, vol. 4, pp. 1-19.

Chu, A.C., Cozzi, G. and Liao, C.H. (2012). 'Endogenous Fertility and Human Capital in a Schumpeterian Growth Model', Journal of Population Economics (forthcoming)

Cigno, A. and Rosati, F.C. (1996). 'Jointly Determined Saving and Fertility Behaviour: Theory and Estimates for Germany, Italy, UK and USA', European Economic Review, vol. 40, pp. 1561-89.

Constantinides, G. (1990). 'Habit Formation: A Resolution of the Equity Premium Puzzle', Journal of Political Economy, vol. 98, pp. 519-43. 
Corrado, L. and Holly, S. (2011). 'Multiplicative Habit Formation and Consumption: A Note', Economics Letters, vol. 113, 116-19.

Das, M. (2003). 'Optimal Growth with Decreasing Marginal Impatience', Journal of Economic Dynamics and Control, vol. 27, pp. 1881-98.

De la Croix, D. (1996). 'The Dynamics of Bequeathed Tastes', Economics Letters, vol. 51, pp. 89-96.

Deaton, A. and Muellbauer, J. (1980) Economics and Consumer Behavior, Cambridge: Cambridge University Press.

Dioikitopoulos, E.V. and Kalyvitis, S. (2010). ‘Endogenous Time Preference and Public Policy: Growth and Fiscal Implications', Macroeconomic Dynamics, vol. 14, pp. 243-57.

Doepke, M. (2004). 'Accounting for Fertility Decline During the Transition to Growth', Journal of Economic Growth, vol. 9, pp. 347-83.

Duesenberry, J. (1949). Income, Saving, and the Theory of Consumer Behavior, Cambridge, MA: Harvard University Press.

Dornbusch, R. and Frenkel, J. (1973). 'Inflation and Growth: Alternative Approaches', Journal of Money, Credit and Banking, vol. 50, pp. 141-56.

Drugeon, J.P. (1996). 'Impatience and Long-run Growth', Journal of Economic Dynamics and Control, vol. 20, pp. 281-313.

Drugeon, J.P. (2000). 'On the Roles of Impatience in Homothetic Growth Paths', Economic Theory vol. 15, pp. 139-61.

Edmonds, E.V. and Pavcnik, N. (2006). 'Trade Liberalization and the Allocation of Labor between Households and Markets in a Poor Country', Journal of International Economics, vol. 69, pp. 272-95. Epstein, L.G. (1987). 'A Simple Dynaic General Equilibrium Model', Journal of Economic Theory, vol. 41 , pp. 68-95.

Fisher, I. (1930). The Theory of Interest, New York: Macmillan.

Flabbi, L. (2010). 'Gender Discrimination Estimation in a Search Model with Matching and Bargaining', International Economic Review, vol. 51, pp. 745-83.

Fuchs, V.R. (1982). Time Preference and Health: An Exploratory Study, in Economic Aspects of Health, edited by Fuchs, University of Chicago Press, V.R. Chicago.

Galor, O. and Weil, D.N. (1996). 'The Gender Gap, Fertility, and Growth', American Economic Review, vol. 86 , pp. 374-87

Galor, O. and Weil, D. (1999). 'From Malthusian Stagnation to Modern Growth', American Economic Review, vol. 89, pp.150-54.

Gómez M.A. (2008). 'Convergence Speed in the AK Endogenous Growth Model with Habit Formation', Economics Letter, vol. 100, pp. 16-21.

Goodfriend, M. and McDermott, J. (1995). 'Early Development', American Economic Review, vol. 85, pp. 116-33.

Haavelmo, T. (1954). A Study in the Theory of Economic Evolution, Amsterdam, North-Holland.

Hazan, M. and Zoabi, H. (2006). 'Does Longevity Cause Growth? A Theoretical Critique', Journal of Economic Growth, vol. 11, pp. 363-76.

Heijdra, B.J. and Romp, W.E. (2008). 'A Life-cycle Overlapping-generations Model of the Small Open Economy', Oxford Economic Papers, vol. 60, pp. 88-121.

Hirose, K.I. and Ikeda, S. (2008). 'On Decreasing Marginal Impatience', Japanese Economic Review, vol. 59, pp. 259-74.

Hock, H. and Weil, D.N. (2012). 'On the Dynamics of the Age Structure, Dependency, and Consumption', Journal of Population Economics, vol. 25, pp. 1019-43.

Horioka, C. (1990). 'Why Is Japan's Households Saving So High? A Literature Survey', Journal of the Japanese and International Economics, vol. 4, pp. 49-92.

Huang, M.M. (2012). 'Housing Deep-Habit Model: Mutual Implications of Macroeconomics and Asset Pricing', Economics Letters, vol. 116, pp. 526-30.

Kam, E. and Mohsin, M. (2006). 'Monetary Policy and Endogenous Time Preference', Journal of Economic Studies, vol. 33, pp. 52-67. 
Kelly, M. (1997). 'The Dynamics of Smithian Growth', Quarterly Journal of Economics, vol. 112, pp. 939-64.

Kirby, K.N., Godoy, R., Reyes-Garcia, V., Byron, B., Apaza, L., Leonard, W., Perez, B., Vadez, V., and Wilkie, D. (2002). 'Correlates of Delay-Discount Rates: Evidence from Tsimane Amerindians of the Bolivia Rain Forest', Journal of Economic Psychology, vol. 23, pp. 291-316.

Kirk, D. (1996). 'Demographic Transition Theory', Population Studies, vol. 50, pp. 361-87.

Lancia, F. and Prarolo, G. (2012). 'A Politico-Economic Model of Aging, Technology Adoption and Growth', Journal of Population Economics, vol. 25, pp. 989-1018.

Lee, R. and Mason, A. (2010). 'Fertility, Human Capital, and Economic Growth over the Demographic Transition', European Journal of Population, vol. 26, pp. 159-82.

Lise, L. and Seitz, S. (2011). 'Consumption Inequality and Intra-Household Allocations', The Review of Economic Studies, vol. 78, pp. 328-55.

Ludwig, A. and Vogel, E. (2009).. 'Mortality, Fertility, Education and Capital Accumulation in a Simple OLG Economy', Journal of Population Economics, vol. 23, pp. 703-35.

Ludwig, A., Schelkle, T., and Vogel, E. (2012). 'Demographic Change, Human Capital and Welfare', Review of Economic Dynamics, vol. 15, pp. 94-107.

Lusardi, A. (1996). 'Permanent Income, Current Income, and Consumption: Evidence from Two Panel Data Set', Journal of Business \& Economic Statistics, vol. 14, pp. 81-90.

Manuelli, R.E. and Seshadri, A. (2009). 'Explaining International Fertility Differences', Quarterly Journal of Economics, vol. 124, pp. 771-807.

Mehra, R. and Prescott, E. (1985). 'The Equity Premium: A Puzzle', Journal of Monetary Economics, vol. 15, pp. 145-61.

Meng, Q. (2006). 'Impatience and Equilibrium Indeterminacy', Journal of Economic Dynamics and Control, vol. 30, pp. 2671-92

Miles, D. and Scott, A. (2005). Macroeconomics - Understanding the Wealth of Nations, Chichester: John Wiley \& Sons Ltd.

Obstfeld, M. (1990). 'Intertemporal Dependence, Impatience, and Dynamics', Journal of Monetary Economics, vol. 26, pp. 45-75.

Olsen, J.A. (1993). 'Time Preference for Health Gains: An Empirical Investigation', Health Economics, vol. 2, pp. 257-65.

Orphanides, A. and Solow, R. (1990). Money, Inflation and Growth, in Handbook of Monetary Economics, edited by Friedman, B. and Hahn, F., Amsterdam: North-Holland.

Palivos, T., Wang, P., and Zhang, J. (1997). 'On the Existence of Balanced Equilibrium', International Economic Review, vol. 38, pp. 205-24.

Persson, T. and Svensson, L. (1985). 'Current Account Dynamics and the Terms of Trade: Harberger-Laursen-Metzler Two Generations Later', Journal of Political Economy, vol. 93, pp. 43-65. Pollak, R. (1970). 'Habit Formation and Dynamic Demand Functions', Journal of Political Economy, vol. 78, pp. 745-63.

Ravn, M., Schmitt-Grohe, S., and Uribe, M. (2006) 'Deep Habits', Review of Economic Studies, vol. 73, pp. 195-218.

Razin, A. and Ben-Zion, U. (1975). 'An Intergenerational Model of Population Growth', American Economic Review, vol. 65, pp. 923-33.

Robinson, J.A. and Srinivasan, T.N. (1997). Long-term Consequence of Population Growth: Technological Change, Natural Resources, and the Environment, in Handbook of Population and Family Economics, edited by Rozenzweig, M.R. and Stark, O., Amsterdam: North-Holland.

Schultz, P.T. (1993). 'Mortality Decline in the Low-Income World: Causes and Consequences', American Economic Review, vol. 83, pp. 337-42.

Schultz, P.T. (1998). 'Health and Schooling Investments in Africa', The Journal of Economic Perspectives, vol. 13, pp. 67-88.

Sheldon, G. (1997). Molding Japanese Minds: The State in Everyday Life, Princeton University Press, Princeton NJ.

Shin, S. and Epstein, L.G. (1993). 'Habits and Time Preference', International Economic Review, vol. 
34 , pp. 61-84.

Smithin, J. (2004). Controversies in Monetary Economies, Cheltenham: Edward Elgar.

Solow, R. (1956). 'A Contribution to the Theory of Growth', Quarterly Journal of Economics, vol. 70, pp. 65-94.

Stern, M.L. (2006). ‘Endogeneous Time Preference and Optimal Growth', Economic Theory, vol. 29, pp. 49-70.

Storesletten, K., Telmer, C., and Yaron, A. (2004). 'Consumption and Risk Sharing over the Life Cycle', Journal of Monetary Economics, vol. 51, pp. 609-33.

Stutzer, M. (1980). 'Chaotic Dynamics and Bifurcation in a Macro Economics', Journal of Economic Dynamics and Control, vol. 2, pp. 253-73.

Sundaresan, S.M. (1989). 'Intertemporally Dependent Preferences and the Volatility of Consumption and Wealth', Review of Financial Studies, vol. 2, pp. 73-89.

Uzawa, H. (1968). 'Time Preference, the Consumption Function, and Optimum Asset Holdings, in Value, Capital and Growth', Papers in Honor of Sir John Hicks, edited by Wolfe, J.N., pp. 485-504, Chicago: Aldine.

Varvarigos, D. and Zakaria, I.Z. (2013). 'Endogenous Fertility in a Growth Model with Public and Private Health Expenditures', Journal of Population Economics, vol. 26, pp. 67-85.

Yip, C. and Zhang, J. (1997). 'A Simple Endogenous Growth Model with Endogenous Fertility: Indeterminacy and Uniqueness', Journal of Population Economics, vol. 10, pp. 97-100.

Zhang, W.B. (1993). 'Woman's Labor Participation and Economic Growth - Creativity, Knowledge Utilization and Family Preference', Economics Letters, vol. 42, pp. 105-10.

Zhang, W.B. (2012). 'Habits, Saving Propensity, and Economic Growth', Scientific Bulletin Economic Sciences, vol. 11, pp. 3-15.

Zhang, W.B. (2013). 'Habit Formation and Preference Change in a Two-sector Growth Model with Elastic Labor Supply', Academica Science Journal: Economica Series, vol. 1, pp. 3-20.

Zhang, W.B. (2015). 'Birth and Mortality Rates, Gender Division of Labor, and Time Distribution in the Solow Growth Model', Revista Galega de Economía, vol. 24, no. 1, pp. 121-34.

\section{Bio-note:}

Wei-Bin Zhang, PhD (Umeå, Sweden), is Associate Dean of International Cooperation and Research Division, Professor of Economics in Ritsumeikan Asia Pacific University (APU), Japan. His main research fields are nonlinear economic dynamics, growth theory, trade theory, East Asian economic development, and Confucianism. He has published about 240 academic articles (150 in peer-review international journals), authorized 22 academic books in English by international publishing houses. Prof. Zhang is editorial board members of 12 international journals. He is currently Top Author in Japan in economics in NJP

(http://ideas.repec.org/top/top.person.anbpages.html) 